\title{
Comparison between Different Shapes of Structure by Response Spectrum Method of Dynamic Analysis
}

\author{
Jaya Rajkumar Ramchandani, Madhuri Nilesh Mangulkar \\ Department of Civil Engineering, J.N.E.C, Aurangabad (M.S), India \\ Email: sharewith_jaya@live.com, mangulkarm@yahoo.com
}

Received 23 January 2016; accepted 11 March 2016; published 14 March 2016

Copyright $@ 2016$ by authors and Scientific Research Publishing Inc.

This work is licensed under the Creative Commons Attribution International License (CC BY). http://creativecommons.org/licenses/by/4.0/

c) (i) Open Access

\begin{abstract}
Several procedures for non-linear static and dynamic analysis of structures have been developed in recent years. In this paper, the response spectrum analysis is performed on two different shapes i.e. regular and irregular shape of structure by using STAAD PRO. And the comparison results are studied and compared accounting for the earthquake characteristics and the structure dynamic characteristics. As the results show that the earthquake response peak values and the main response frequencies are very close and comparable. It can be referred to by the engineering applications.
\end{abstract}

\section{Keywords}

Seismic Response Spectrum Analysis, STAAD PRO, Dynamic Characteristics, Earthquake Response Peak

\section{Introduction}

Response spectrum is one of the useful tools of earthquake engineering for analyzing the performance of structures especially in earthquakes, since many systems behave as single degree of freedom systems. Thus, if you can find out the natural frequency of the structure, then the peak response of the building can be estimated by reading the value from the ground response spectrum for the appropriate frequency. In most building codes in seismic regions, this value forms the basis for calculating the forces that a structure must be designed to resist (seismic analysis).

A response spectrum is a plot of the maximum response amplitude (displacement, velocity or acceleration) versus time period of many linear single degree of freedom oscillators to a give component of ground motion. 
The resulting plot can be used to select the response of any linear SDOF oscillator, given its natural frequency of oscillation. One such use is in assessing the peak response of buildings to earthquakes.

In Payam Tehrani [2006] study, he compared the nonlinear static (pushover) and nonlinear dynamic procedures in the determination of maximum displacements of an existing steel structure retrofitted with different methods [1]. In A. R. Touqan [2008] a comparison of the Response spectrum analysis and Equivalent Static Lateral Load with the more elaborate Response Spectrum Method of analysis as they apply to a repertoire of different structural models [2]. In Prof Dr. Qaiseruz Zaman Khan's [2010] paper Response spectrum analysis of 20 story building has been discussed in detail and comparison of static and dynamic analysis and design results of buildings up to 400 feet height ( 40 story) in terms of percentage decrease in bending moments and shear force of beams, bending moments of columns, top story deflection and support reaction are discussed [3]. Romy Mohan [2011] paper highlights the accuracy and exactness of Time History analysis in comparison with the most commonly adopted response spectrum analysis and equivalent static analysis considering different shape of shear walls [4].

In this paper, a four storey reinforced concrete building with moment resisting frame of different shapes i.e., Regular shaped and Irregular shaped is analyzed by Response spectrum method of Dynamic analysis of Earthquake. A set of values from 0 to 90 degrees with an increment of 10 degrees have been used of excitation of seismic force. The details of the study and its result are described briefly in the following section of the paper.

\section{Parametric Details of Model}

The position of three different types of columns C1, C2, C3 i.e. corner, side and middle respectively of Regular (Square) and Irregular structure is shown in Figure 1 and Figure 2 respectively. And Table 1 represents all the basic specification required for the analysis of the structure.

\section{Methodology}

The present study undertaken deals with response spectrum method of dynamic analysis. In order to apply forces in different angles, the structure has to be rotated with incidence angle from 0 to 90 degrees, with an increment of 10 degrees and column forces have been investigated in all cases. Further in order to find the accurate angle the interval of one degree is used. The columns have been divided into three main categories, including corner, side and internal (middle) columns and the results are compared.

\section{Results and Discussion}

Table 2 and Table 3 show the values of shear force, moment about $\mathrm{Y}$ axis and moment about $\mathrm{Z}$ axis for square (regular) and irregular shaped structure for three different types of columns C1 (Corner), C2 (Side), C3 (Middle) respectively. And Figure 3 to Figure 8 show the graph of these values v/s angle of rotation in degrees.

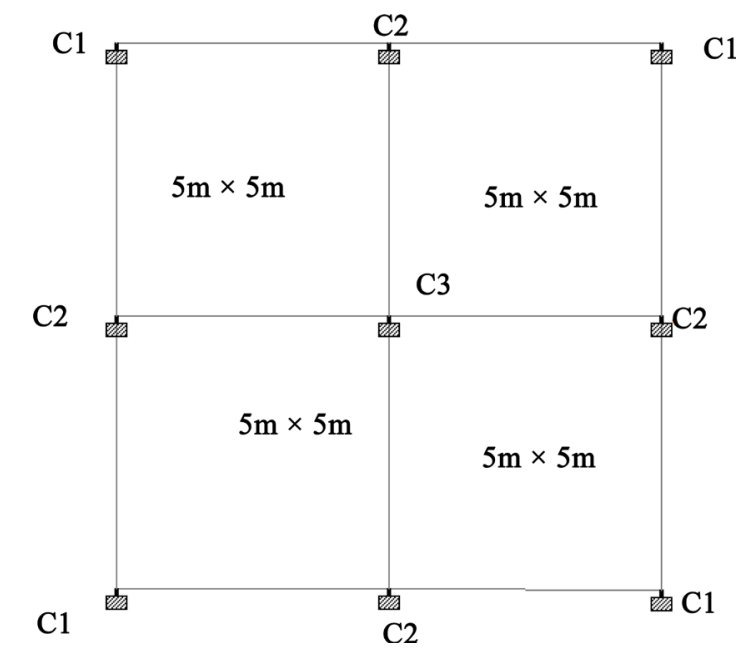

Figure 1. Regular square structure. 


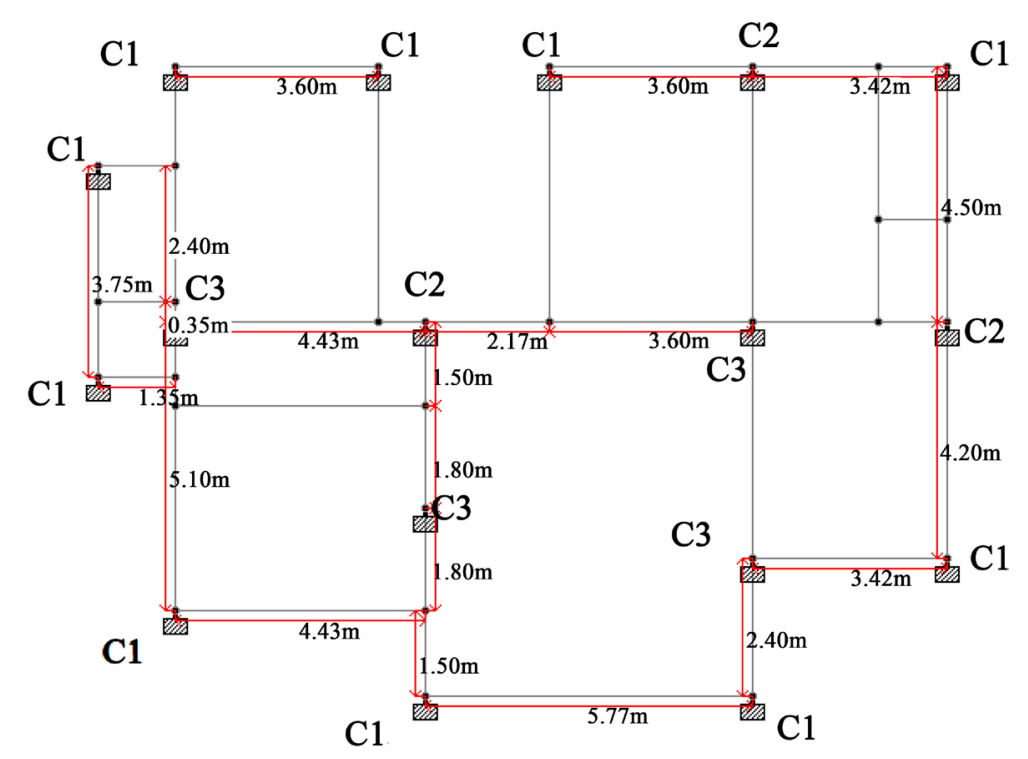

Figure 2. Irregular structure.

\section{Table 1. Specification of models.}

\begin{tabular}{cc}
\hline Type of Structure & G +4 Storied Rigid Jointed frame (RC Moment Resisting Frame) \\
\hline Seismic Zone & V, As per IS 1893 Part I, Z = 0.36 \\
Importance Factor & For All General Buildings = 1 \\
Rock and Hard Soil Site Factor & Hard Soil = 1 \\
Damping Ratio & 0.05 \\
Imposed load & $2 \mathrm{kN} / \mathrm{m}^{2}$ \\
Storey Height & $3.15 \mathrm{~m}$ \\
Specific Weight of RCC & $25 \mathrm{kN} / \mathrm{m}^{3}$ \\
Specific Weight of Brick Infill & $18 \mathrm{kN} / \mathrm{m}^{3}$ \\
Infill Wall & $150 \mathrm{~mm}$ \\
Corner Columns Size C1 & $230 \times 380 \mathrm{~mm}$ \\
Side Columns Size C2 & $300 \times 380 \mathrm{~mm}$ \\
Middle Columns Size C3 & $300 \times 450 \mathrm{~mm}$ \\
\hline
\end{tabular}

Table 2. (a) Square corner column C1, (b) square side column C2, (c) square middle column C3.

(a)

\begin{tabular}{ccccc}
\hline ANGLE & SHEAR+ & SHEAR- & My & Mz \\
\hline 0 & 970.012 & 22.407 & 30.192 & 35.383 \\
10 & 970.387 & 25.826 & 30.063 & 35.243 \\
20 & 970.579 & 28.443 & 29.726 & 34.869 \\
30 & 970.568 & 30.167 & 29.002 & 34.663 \\
40 & 970.338 & 30.956 & 28.069 & 33.125 \\
50 & 970.335 & 30.95 & 28.042 & 33.125 \\
60 & 970.571 & 30.157 & 29.004 & 34.114 \\
70 & 970.574 & 28.436 & 29.726 & 34.85 \\
80 & 970.362 & 25.829 & 30.079 & 35.307 \\
90 & 970.012 & 22.407 & 30.192 & 35.383 \\
\hline
\end{tabular}


(b)

\begin{tabular}{|c|c|c|c|c|}
\hline ANGLE & SHEAR+ & SHEAR- & My & Mz \\
\hline 0 & 1800 & 36.428 & 57.846 & 70.539 \\
\hline 10 & 1800 & 35.861 & 57.845 & 70.538 \\
\hline 20 & 1800 & 34.187 & 57.844 & 70.539 \\
\hline 30 & 1800 & 31.502 & 57.846 & 71.822 \\
\hline 40 & 1800 & 27.906 & 57.845 & 70.539 \\
\hline 50 & 1800 & 27.915 & 57.845 & 70.539 \\
\hline 60 & 1800 & 31.509 & 57.845 & 70.539 \\
\hline 70 & 1800 & 34.178 & 57.846 & 70.539 \\
\hline 80 & 1800 & 35.856 & 57.846 & 70.539 \\
\hline 90 & 1800 & 36.428 & 57.846 & 70.539 \\
\hline \multicolumn{5}{|c|}{ (c) } \\
\hline ANGLE & SHEAR+ & SHEAR- & My & $\mathbf{M z}$ \\
\hline 0 & 2630 & 0 & 34.007 & 76.776 \\
\hline 10 & 2630 & 0.013 & 33.435 & 77.903 \\
\hline 20 & 2630 & 0.026 & 31.826 & 83.024 \\
\hline 30 & 2630 & 0.035 & 32.734 & 88.858 \\
\hline 40 & 2630 & 0.038 & 48.696 & 90.263 \\
\hline 50 & 2630 & 0.034 & 61.298 & 78.24 \\
\hline 60 & 2630 & 0.024 & 64.879 & 55.101 \\
\hline 70 & 2630 & 0.012 & 63.401 & 41.277 \\
\hline 80 & 2630 & 0.003 & 61.659 & 42.388 \\
\hline 90 & 2630 & 0 & 60.996 & 42.68 \\
\hline
\end{tabular}

Table 3. (a) Irregular corner column C1, (b) irregular side column C2, (c) irregular middle column C3.

(a)

\begin{tabular}{ccccc}
\hline ANGLE & SHEAR+ & SHEAR- & My & Mz \\
\hline 0 & 1490 & 498.005 & 113.578 & 151.874 \\
10 & 1510 & 449.561 & 111.365 & 150.096 \\
20 & 1500 & 462.702 & 106.863 & 145.736 \\
30 & 1480 & 467.989 & 100.753 & 152.748 \\
40 & 1530 & 460.181 & 92.826 & 146.705 \\
50 & 1560 & 437.8 & 93.146 & 144.016 \\
60 & 1570 & 435.481 & 102.2 & 141.085 \\
70 & 1560 & 414.88 & 108.509 & 147.596 \\
80 & 1520 & 373.862 & 111.489 & 151.09 \\
90 & 1490 & 388.607 & 113.578 & 151.874 \\
\hline & & $(b)$ & & \\
ANGLE & SHEAR+ & SHEAR- & My & Mz \\
\hline 0 & 2130 & 304.889 & 208.223 & 212.46 \\
10 & 2170 & 294.171 & 208.431 & 210.068 \\
20 & 2200 & 273.37 & 202.316 & 202.152 \\
30 & 2210 & 281.698 & 190.323 & 188.827 \\
\hline
\end{tabular}




\begin{tabular}{ccccc} 
Continued & & & & \\
\hline 40 & 2200 & 313.914 & 172.83 & 170.256 \\
50 & 2200 & 375.673 & 194.204 & 167.194 \\
60 & 2180 & 424.402 & 175.391 & 186.58 \\
70 & 2140 & 459.777 & 189.406 & 200.649 \\
80 & 2100 & 482.009 & 201.666 & 209.302 \\
90 & 2130 & 491.464 & 208.223 & 212.46 \\
\hline & & $(c)$ & & \\
\hline ANGLE & SHEAR+ & SHEAR- & My & Mz \\
\hline 0 & 2360 & 327.852 & 263.663 & 310.705 \\
10 & 2340 & 337.015 & 261.208 & 307.573 \\
20 & 2320 & 339.325 & 250.968 & 296.569 \\
30 & 2290 & 334.766 & 233.18 & 278.177 \\
40 & 2240 & 322.064 & 208.368 & 252.987 \\
50 & 2280 & 299.139 & 204.524 & 244.832 \\
60 & 2320 & 264.573 & 228.088 & 272.289 \\
70 & 2340 & 269.179 & 247.877 & 292.813 \\
80 & 2360 & 275.786 & 259.901 & 305.753 \\
90 & 2360 & 275.524 & 263.662 & 310.705 \\
\hline
\end{tabular}

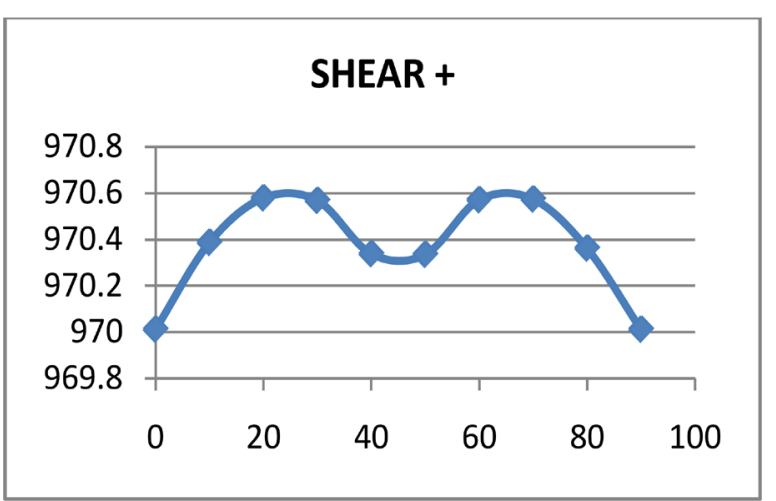

(a)

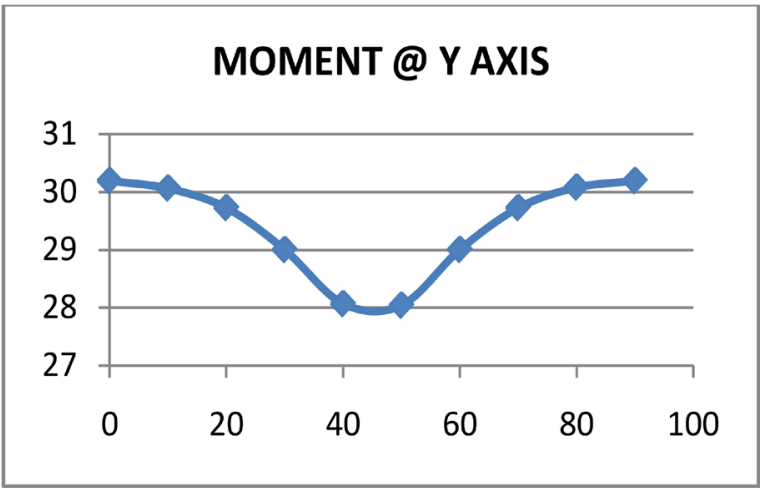

(b)

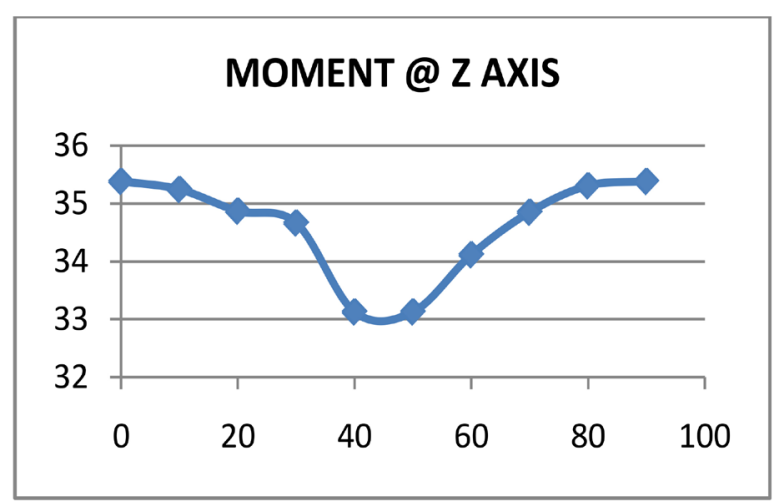

(c)

Figure 3. (a) Graph of Fx v/s angle of rotation in degrees, (b) graph of My v/s angle of rotation in degrees, (c) graph of Mz $\mathrm{v} / \mathrm{s}$ angle of rotation in degrees. 


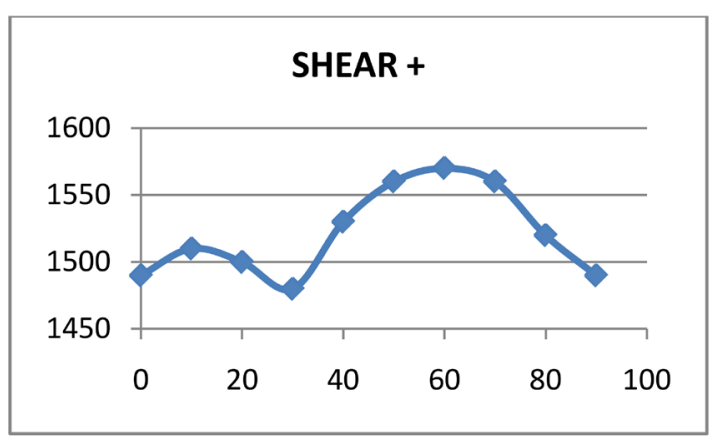

(a)

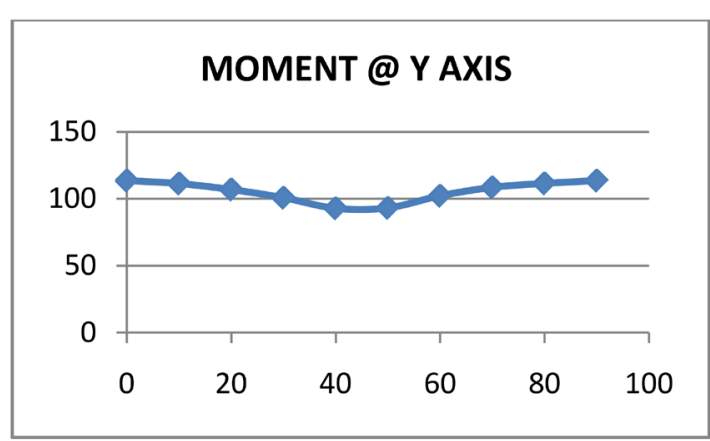

(b)

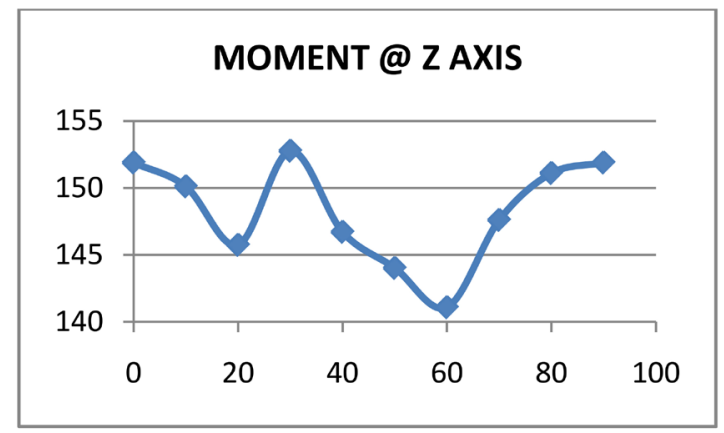

(c)

Figure 4. (a) Graph of Fx v/s angle of rotation in degrees, (b) graph of My v/s angle of rotation in degrees, (c) graph of $\mathrm{Mz} \mathrm{v} / \mathrm{s}$ angle of rotation in degrees.

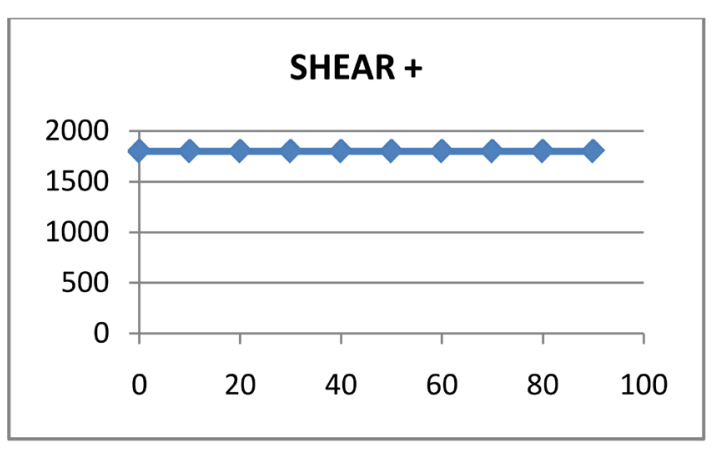

(a)

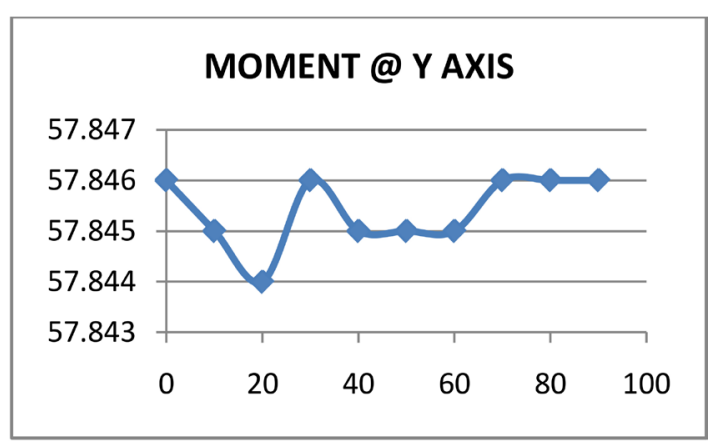

(b)

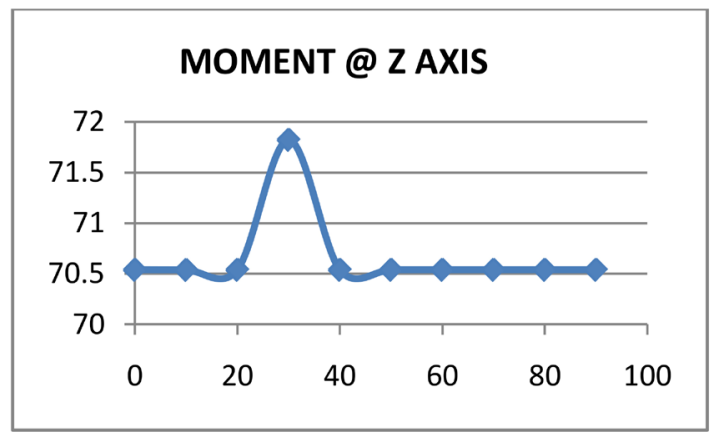

(c)

Figure 5. (a) Graph of Fx v/s angle of rotation in degrees, (b) graph of My v/s angle of rotation in degrees, (c) graph of $\mathrm{Mz} \mathrm{v} / \mathrm{s}$ angle of rotation in degrees. 


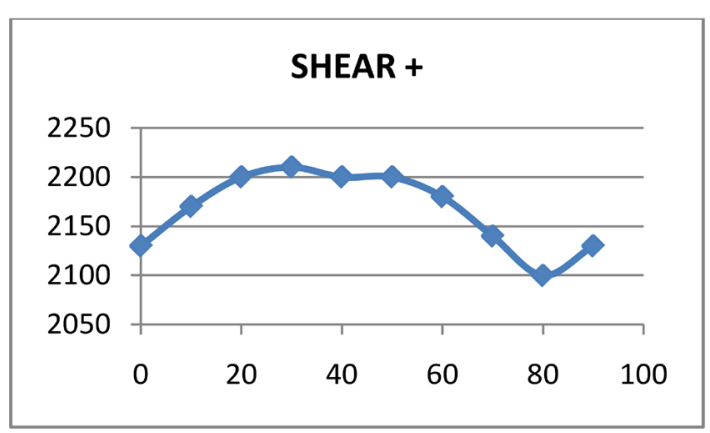

(a)

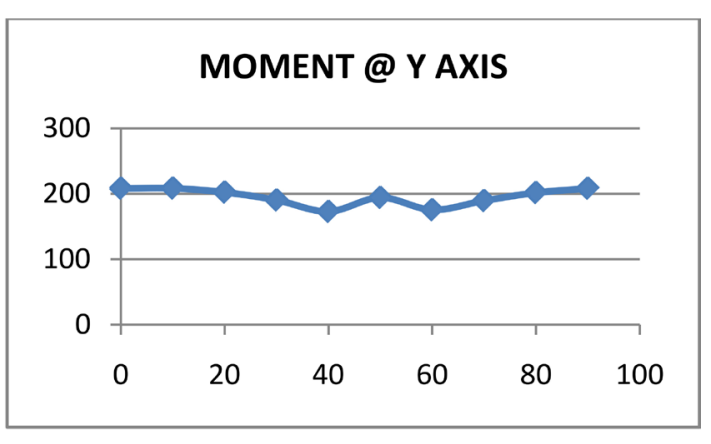

(b)

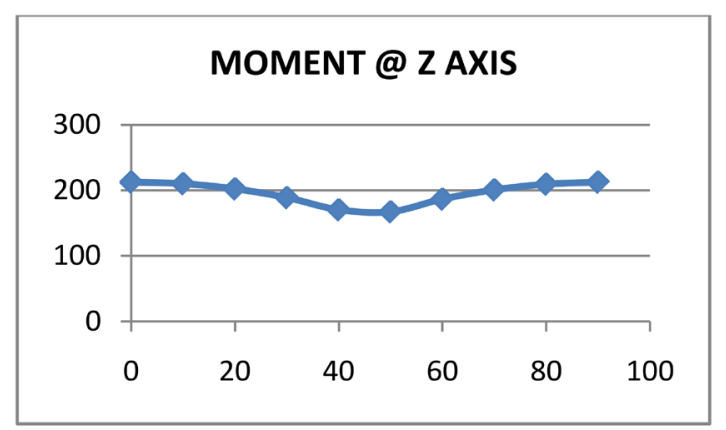

(c)

Figure 6. (a) Graph of Fx v/s angle of rotation in degrees, (b) graph of My v/s angle of rotation in degrees, (c) graph of $\mathrm{Mz} \mathrm{v} / \mathrm{s}$ angle of rotation in degrees.

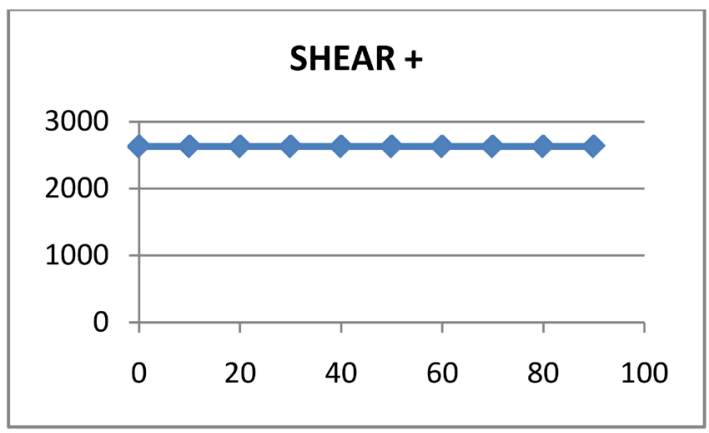

(a)

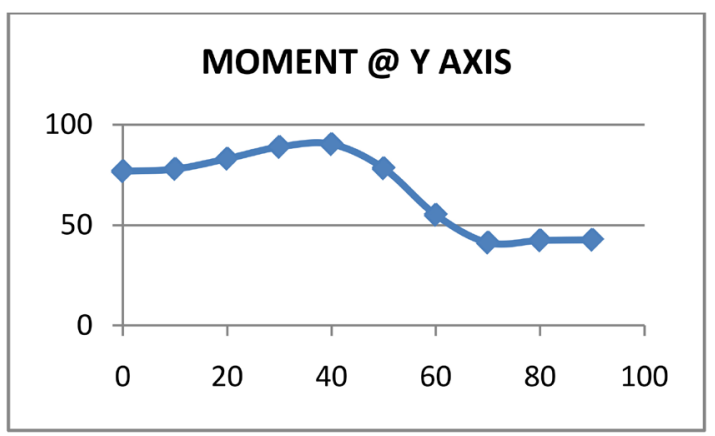

(b)

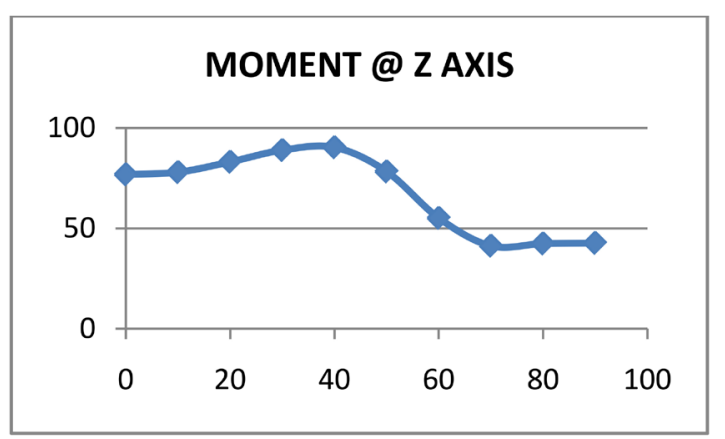

(c)

Figure 7. (a) Graph of Fx v/s angle of rotation in degrees, (b) graph of My v/s angle of rotation in degrees, (c) graph of $\mathrm{Mz}$ v/s angle of rotation in degrees. 


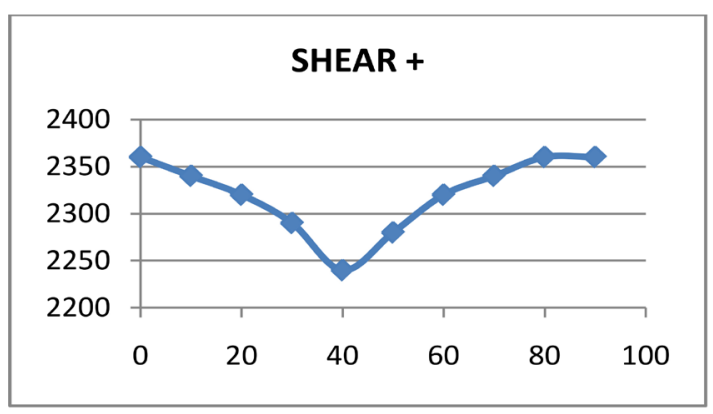

(a)

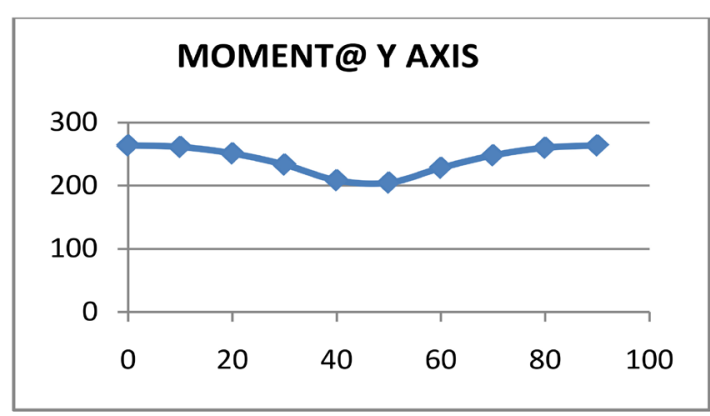

(b)

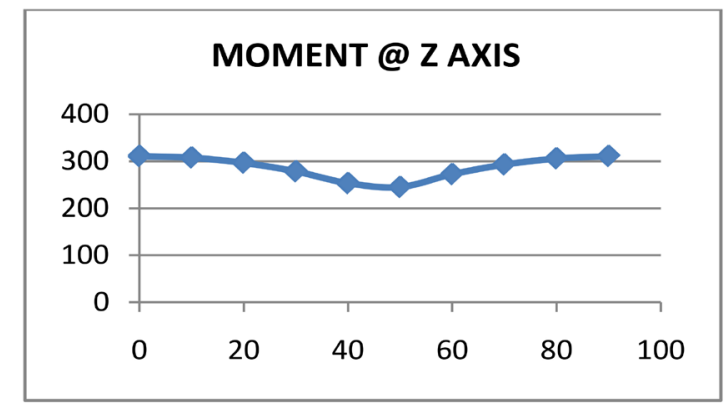

(c)

Figure 8. (a) Graph of Fx v/s angle of rotation in degrees, (b) graph of My v/s angle of rotation in degrees, (c) graph of $\mathrm{Mz} \mathrm{v} / \mathrm{s}$ angle of rotation in degrees.

\section{Conclusions}

1) For Corner Column C1: The shear force along $X$ direction has a symmetrical parabolic curve about $Y$ axis for regular square structure whereas for irregular structure the curve is un-symmetric as shown in Figure 3(a) and Figure 4(a) respectively.

2) The graph of Moment about $Y$ axis is symmetrical about $Y$ axis for both the structures. And the graph of Moment about $\mathrm{Z}$ axis is unsymmetrical for both the structures as shown in Figure 3(c) and Figure 4(c) respectively.

3) For Side Column C2: The shear force in $X$ direction is constant throughout for regular square structure whereas for irregular structure the curve is symmetric about $\mathrm{Y}$ axis which attains maximum value at 30 degrees as shown in Figure 5(a) and Figure 6(a) respectively.

4) Similarly the graphs for moments about $Y$ and $Z$ axis can be compared for both the structures.

5) For Middle Column C3: Again the shear along $X$ direction is constant for regular square structure and symmetric parabolic nature for irregular structure.

6) The above conclusions show that structure behaves in different manner for different shape of structure. Thus, the structure should be analyzed for each particular angle and it should be designed for maximum value of shear force and maximum moments.

\section{References}

[1] Patil, A.S. and Kumbhar, P.D. (2013) Time History Analysis of Multi Storied RCC Buildings for Different Seismic Intensities. International Journal of Structural and Civil Engineering, 2, 194-197.

[2] Bedekar, S. and Shinde, R. (2015) Time History Analysis of High Rise Structure Using Different Accelerogram. International Journal of Research in Engineering and Advanced Technology, 3, 1108-1111.

[3] Hosseini, M. and Salemi, A. (2008) Studying Effect of Earthquake Excitation Angle on Internal Forces of Steel Buildings Elements by Using Non Linear Time History Analysis. The 14th World Conference on Earthquake Engineering, Beijing, 12-17 October 2008, 343-348.

[4] Duggal, S.K. (2010) Earthquake Resistance Design of Structure. 4th Edition, Oxford University Press, New Delhi. 